\title{
Similar or Not? Comparison of Dissolution Profiles of Different Hydroxypropylmethyl Cellulose (HPMC) Capsules
}

\author{
Jozef Al-Gousous ${ }^{1}$, Michael B. Bolger², Fernando Diez ${ }^{3}$, Justin Kalafat ${ }^{3}$, Peter Langguth ${ }^{*}$ \\ ${ }^{1}$ Institute of Pharmacy and Biochemistry, Johannes Gutenberg University, Mainz, Germany \\ ${ }^{2}$ Simulations Plus Inc, Lancaster, CA, USA
}

${ }^{3}$ ACG World, Mumbai, India

e-mail: langguth@uni-mainz.de

\section{ABSTRACT}

The effect of using different HPMC hard capsule shells on the in vitro dissolution profile of acetaminophen powder was investigated. Use of HPMC capsule shells from different manufacturers resulted in different in vitro dissolution profiles. These differences were unrelated to the presence or absence of a gelling agent (carrageenan) in the capsule shells when potassium was absent from the dissolution media. Even though these differences can be significant from a regulatory point of view, they do not translate into differences in the in vivo performance. This is because, in some cases, the similarity criterion of $f_{2} \geq 50$ is too strict.

KEYWORDS: Capsules, HPMC, dissolution, similarity factor, simulation

\section{INTRODUCTION}

$\mathrm{H}$ ard shell capsules, along with tablets, are the most common dosage forms for oral administration of solid state pharmaceuticals and nutraceuticals. One of the main advantages of capsules as a dosage form is the time to market. In standard conditions, the time needed to develop the drug is shorter if a capsule is selected. The time reduction increases R\&D productivity, compensating for potential loss of revenue due to expiring patent protection for successful products. This fact, in addition to the cost, explains the growing demand for the capsule dosage form.

Gelatin capsules are the most commonly used; however, in recent years, hydroxypropylmethyl cellulose (HPMC) capsules have been rising to the fore. HPMC capsules are often preferred for moisture-sensitive active pharmaceutical ingredients (APIs) (e.g. dabigatran etexilate) and APIs that can react with gelatin (e.g. aldehydes) $(1,2)$. Moreover, HPMC capsules are increasingly favored by the nutritional supplement industry owing to the "natural" image they can confer on the product for marketing purposes. Last, but not least, HPMC capsules are not made with animal by-products; this distinct characteristic allows them to be suitable for individuals who choose not to consume products sourced

${ }^{*}$ Corresponding author. from animals. Apart from being the obvious choice for both vegetarian and vegan consumers, HPMC capsules are also more acceptable for religious reasons as well. In fact, HPMC capsules are often deemed suitable to be classified as both Kosher and Halal products.

Two main types of HPMC capsules exist on market: ones manufactured with a gelling agent (typically on the carrageenan) added to the HPMC solution, and ones where the gelation of the HPMC solution is induced thermally (no gelling agent added). The thermally gelled capsules have the advantage of their release performance being unaffected by potassium and calcium ions (2).

The purpose of this study was to compare the effect of using HPMC hard capsule shells of both types from different vendors on the in vitro dissolution performance of the final product. In addition, the potential of such differences translating into differences in the in vivo pharmacokinetic profiles was investigated as well.

\section{MATERIALS AND METHODS}

\section{Materials}

The capsules used were the gelling agent (carrageenan)containing ACG Nature Caps (ACG World, India) and Quali-V capsules (Qualicaps Europe, Spain), and the gelling agent-free ACG Nature Caps Plus (ACG World, India) and 
Vcaps Plus (Capsugel, France). All the capsules were size 0. Acetaminophen was obtained from Sri Krishna Pharmaceuticals (Hyderabad, India). All other materials used were of analytical grade.

\section{Capsule filling}

Each capsule was filled with 300 mg of acetaminophen by hand.

\section{Dissolution testing}

Dissolution testing was performed using a United States Pharmacopoeia (USP) type II apparatus (iDisso-12, Electrolab, Mumbai, India) and USP sinkers (iDisso-12).

The media used to conduct the tests were: $0.1 \mathrm{M} \mathrm{HCl}, \mathrm{pH}$ 4.5 acetate buffer, and $2^{\text {nd }}$ dissolution fluid of the Japanese Pharmacopeia (JP) with the potassium phosphate being replaced by an equimolar level of sodium phosphate. Samples (5-mL) were removed and replaced with fresh dissolution medium at $5,10,15,30$, and 45 minutes after the start of the test. The filtered samples were then assayed for acetaminophen spectrophotometrically at a wavelength of $249 \mathrm{~nm}$ (Evolution 201 UV Visible Spectrophotometer, Thermo Fischer Scientific, MA, USA).

\section{Simulations}

GastroPlus $^{\mathrm{TM}}$ v9 (Simulations Plus, USA) was used to perform the simulations. For model validation, reference intravenous (IV), oral solution, and rapidly releasing oral tablet plasma profiles from published literature were fitted with a three-compartment model using the PKPlus module of the GastroPlus Software $(3,4)$. The calculated pharmacokinetic parameters together with a solubility of $27.3 \mathrm{mg} / \mathrm{mL}$ and a jejunal effective permeability $\left(P_{\text {eff }}\right)$ value of $4.8 \times 10^{-4} \mathrm{~cm} / \mathrm{s}$ (Table 1 ) were used to simulate predicted profiles that were compared to published literature $(5,6)$. Because the rapidly dissolving tablet formulation was predicted by the software to fully dissolve in $1 \mathrm{~min}$, the default gastric emptying time for suspensions and solutions $(0.1 \mathrm{~h})$ was used instead of that for tablets $(0.25 \mathrm{~h})$ for the simulation.

Table 1. Pharmacokinetic and Physico-Chemical Parameters Used in Simulations

\begin{tabular}{|c|c|c|}
\hline Parameter & Value & Reference \\
\hline Solubility & $27.3 \mathrm{mg} / \mathrm{mL}$ & (5) \\
\hline $\log P$ & 0.2 & (5) \\
\hline $\begin{array}{l}k_{12} \\
k_{21} \\
k_{13} \\
k_{31}\end{array}$ & $\begin{array}{c}4.224 h^{-1} \\
1.1557 h^{-1} \\
0.63126 h^{-1} \\
0.04883 h^{-1}\end{array}$ & \multirow{4}{*}{$\begin{array}{l}\text { Obtained by fitting } \\
\text { reference intravenous, } \\
\text { oral solution, and } \\
\text { rapidly releasing tablet } \\
\text { pharmacokinetic } \\
\text { profiles from (3) and } \\
\text { (4) using the PKPlus } \\
\text { module of GastroPlus. }\end{array}$} \\
\hline $\mathrm{V}_{\mathrm{c}}$ & $0.14643 \mathrm{~L} / \mathrm{kg}$ & \\
\hline Clearance & $0.21782 \mathrm{~L} \mathrm{~h}^{-1} \mathrm{~kg}^{-1}$ & \\
\hline $\begin{array}{l}\text { Hepatic first pass } \\
\text { extraction }\end{array}$ & $7.5617 \%$ & \\
\hline Permeability ( $\left.P_{\text {eff }}\right)$ & $4.8 \times 10^{-4} \mathrm{~cm} / \mathrm{s}$ & (6) \\
\hline
\end{tabular}

Following validation, these parameters were applied to simulations of the dissolution profiles for the different types of capsules in $0.1 \mathrm{M} \mathrm{HCl}$. For these simulations, a body weight of $71.3 \mathrm{~kg}$, corresponding to the average body weight of the subjects in the validation datasets, was used. GastroPlus includes several immediate release (IR) and controlled release (CR) dosage forms. The acetaminophen capsules tested in this study are considered IR dosage forms, but for the purposes of the GastroPlus simulations, the dosage form selected was " $\mathrm{CR}$ Integral Tablet", so that the software would recognize and load the experimentally determined dissolution profile instead of calculating the dissolution using a NernstBrunner equation. In addition, simulations using the "CRU Integral Tablet" (CRU: controlled release undissolved) dosage form, where the release profile is assumed to be that of undissolved released solid particles, as well as simulations showing the effect of different hypothetical $P_{\text {eff }}$ values and gastric emptying rates were performed. By using the CRU dosage form, the experimental in vitro dissolution profile relates directly to the release of undissolved acetaminophen from the capsule.

\section{Statistical analysis}

The $f_{2}$ values resulting from comparing the dissolution profiles were statistically analyzed using the SPSS version 23 software (IBM, USA).

\section{RESULTS AND DISCUSSION \\ Dissolution Profiles}

The dissolution profiles in different media are shown in Figure 1. The results of paired comparisons through similarity factor $\left(f_{2}\right.$ value) calculation are shown in Table 2. It is clear that using different capsule shells results in different dissolution profiles. Two-way ANOVA with interaction was performed (as shown in Table 3) on the set of $f_{2}$ values to determine whether the presence or absence of gelling agent is the reason behind these differences.

ANOVA indicated that the presence or absence of the gelling agent in the capsule shells of the compared pairs did not have a significant effect on the comparison outcome ( $p$-value $=0.7$ ). This means that other factors like shell thickness, HPMC grade, or manufacturing variables are more likely to be responsible for the differences in dissolution performance. The weight and size specifications of the different manufacturers for the empty capsules do not suggest major potential differences in the shell thicknesses. Therefore, the remaining explanation would be either the use of different HPMC grades and/or some different processing variables, and 


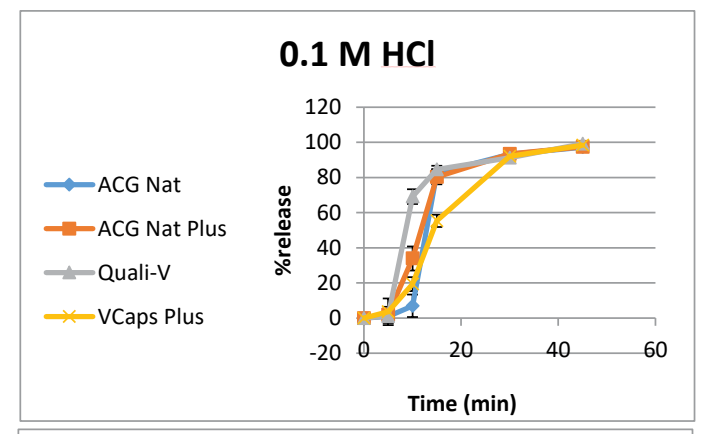

pH 4.5 acetate buffer
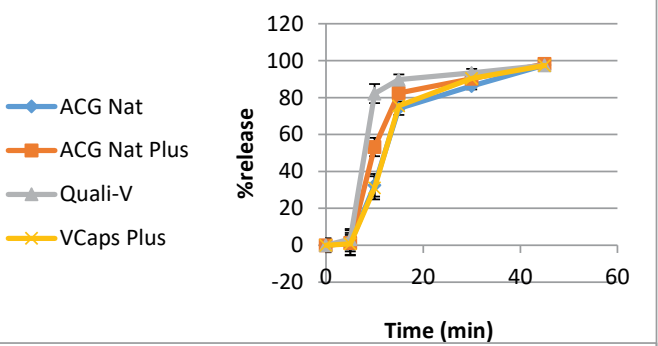

JP 2nd dissolution fluid Na only
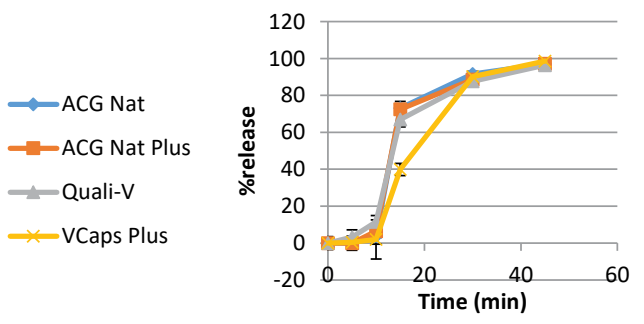

Figure 1. Dissolution profiles of acetaminophen capsules in different media (ACG Nat, ACG Nature Caps; ACG Nat Plus, ACG Nature Caps Plus; $J P$, Japanese Pharmacopiea).

Table 2. Comparison of Dissolution Profiles of Tested Capsules Using $f_{2}$ Value

\begin{tabular}{|c|c|c|c|c|c|c|}
\hline \multirow{2}{*}{\begin{tabular}{c} 
Dissolution \\
\cline { 2 - 7 }
\end{tabular}} & $\begin{array}{c}\text { ACG Nature } \\
\text { Caps vs } \\
\text { ACG Nature } \\
\text { Caps Plus }\end{array}$ & $\begin{array}{c}\text { ACG } \\
\text { Nature } \\
\text { Caps vs } \\
\text { Quali-v }\end{array}$ & $\begin{array}{c}\text { ACG } \\
\text { Nature } \\
\text { Caps vs } \\
\text { Vcaps Plus }\end{array}$ & $\begin{array}{c}\text { ACG } \\
\text { Nature } \\
\text { Caps Plus } \\
\text { vs Quali-V }\end{array}$ & $\begin{array}{c}\text { ACG } \\
\text { Nature } \\
\text { Caps Plus } \\
\text { vs Vcaps } \\
\text { Plus }\end{array}$ & $\begin{array}{c}\text { Quali-v } \\
\text { vs Vcaps } \\
\text { Plus }\end{array}$ \\
\hline $0.1 \mathrm{M} \mathrm{HCl}$ & 43.41 & 25.35 & 41.20 & 37.47 & 41.91 & 26.94 \\
\hline $\begin{array}{c}\text { pH 4.5 } \\
\text { acetate } \\
\text { buffer }\end{array}$ & 47.15 & 28.99 & 80.02 & 41.11 & 46.73 & 28.77 \\
\hline $\begin{array}{c}\text { JP 2 } 2^{\text {nd }} \\
\text { dissolution } \\
\text { fluid with } \\
\text { Na only }\end{array}$ & 82.35 & 62.40 & 38.90 & 68.62 & 39.16 & 41.93 \\
\hline
\end{tabular}

$J P$, Japanese Pharmacopeia.

\begin{tabular}{|c|c|c|c|}
\hline \multirow[b]{2}{*}{$\begin{array}{l}\text { Dissolution } \\
\text { Medium }\end{array}$} & \multicolumn{3}{|c|}{$f_{2}$ Value of the Compared Pair } \\
\hline & $\begin{array}{l}\text { Gelling Agent Present } \\
\text { vs No Gelling Agent }\end{array}$ & $\begin{array}{l}\text { Gelling Agent Present } \\
\text { vs Gelling Agent } \\
\text { Present }\end{array}$ & $\begin{array}{l}\text { No Gelling Agent vs No } \\
\text { Gelling Agent }\end{array}$ \\
\hline $0.1 \mathrm{M} \mathrm{HCl}$ & $\begin{array}{l}43.41 \\
41.20 \\
37.47 \\
26.94 \\
\end{array}$ & 25.35 & 41.91 \\
\hline $\begin{array}{l}\text { pH } 4.5 \\
\text { acetate } \\
\text { buffer }\end{array}$ & $\begin{array}{l}47.15 \\
80.02 \\
41.11 \\
28.77\end{array}$ & 28.99 & 46.73 \\
\hline $\begin{array}{c}\text { JP } 2^{\text {nd }} \\
\text { dissolution } \\
\text { fluid with } \mathrm{Na} \\
\text { only }\end{array}$ & $\begin{array}{l}82.35 \\
38.90 \\
68.62 \\
41.93\end{array}$ & 62.40 & 39.16 \\
\hline
\end{tabular}

$J$, Japanese Pharmacopeia.

this, owing to the full information not being disclosed by the manufacturers, cannot be ascertained in this study. As for the effect of dissolution media on the $f_{2}$ value, it was not shown to be significant either ( $p$-value $=0.387$ ). The same applied to the interaction between the two factors ( $p$-value $=0.771$ ).

In the JP $2^{\text {nd }}$ dissolution fluid, the potassium phosphate specified by the JP was replaced by an equimolar level of the sodium phosphate. This change from potassium to sodium was made because of the well-known releaseretarding effect of potassium ions on carrageenancontaining HPMC capsules, which would not normally be of in vivo significance because normal fasted state gastrointestinal (GI) fluids are poor in potassium $(2,7,8)$.

\section{Simulations}

Figure 2 shows the model validation results. The predicted profiles match well to the observed ones with $\mathrm{C}_{\max }$ and AUC prediction errors not exceeding 10\% (data not shown). Figure 3 shows the predicted pharmacokinetic profiles for the different capsules. Despite the $f_{2}$ values showing the dissolution profiles to be different, and the "very rapidly dissolving" criterion of not less than $85 \%$ released in 15 minutes not being met, the pharmacokinetic profiles are predicted to be similar with the differences in $\mathrm{C}_{\max }$ less than $5 \%(9,10)$. When the simulations were performed using the CRU Integral Tablet, where the drug release is assumed to be that of undissolved drug particles that dissolve later in $\mathrm{Gl}$ fluids, the expected in vivo dissolution profiles were very close to the dissolution profiles of the capsules (Figure 4), indicating that the dissolution of acetaminophen particles is very rapid, so rupture of the capsule shell is the rate-limiting step of the drug release process. 


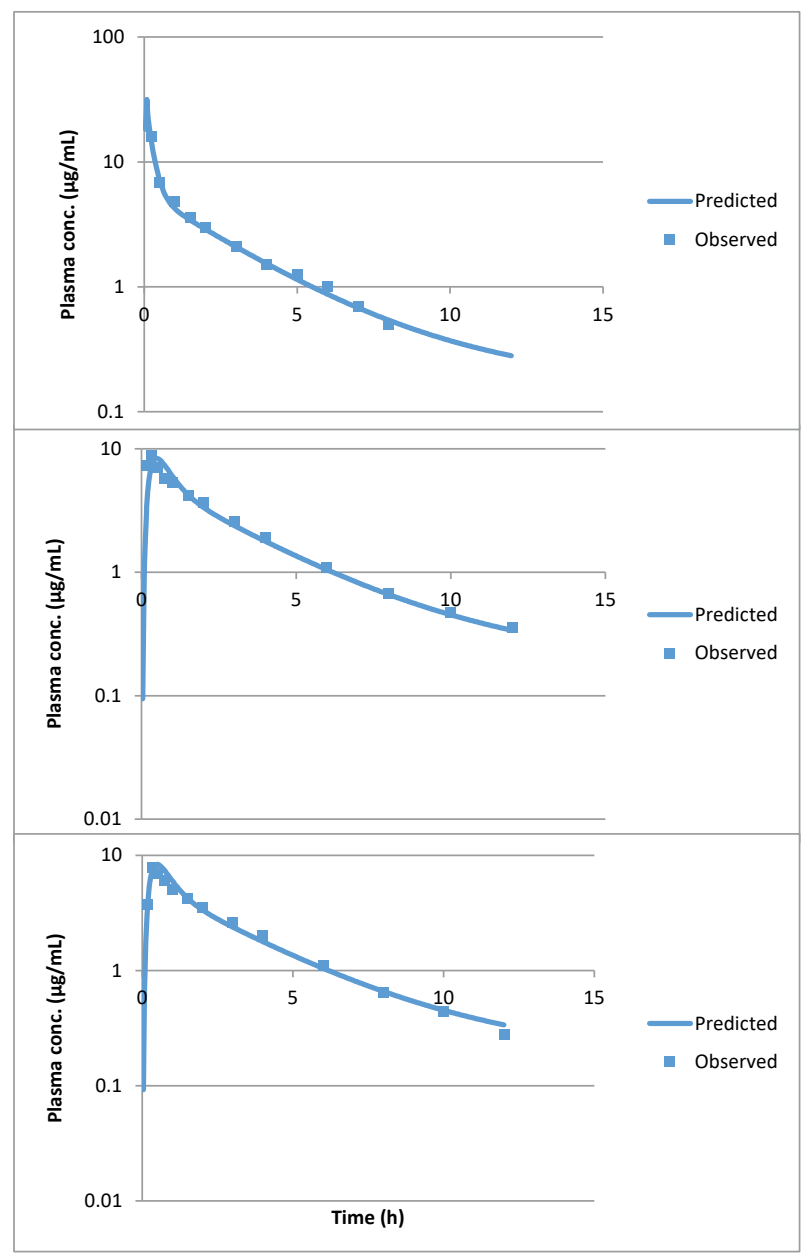

Figure 2. Validation of GastroPlus model for IV administration (top), oral solution (middle), and rapidly releasing oral tablet (bottom).

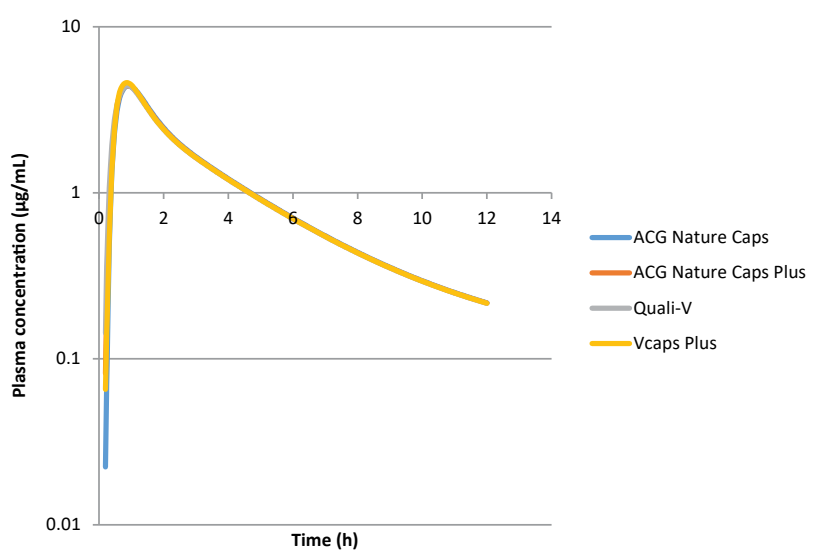

Figure 3. Predicted pharmacokinetic profiles resulting from administration of different capsules.

To investigate the reasons for similarity of pharmacokinetic profiles, simulations were performed with different

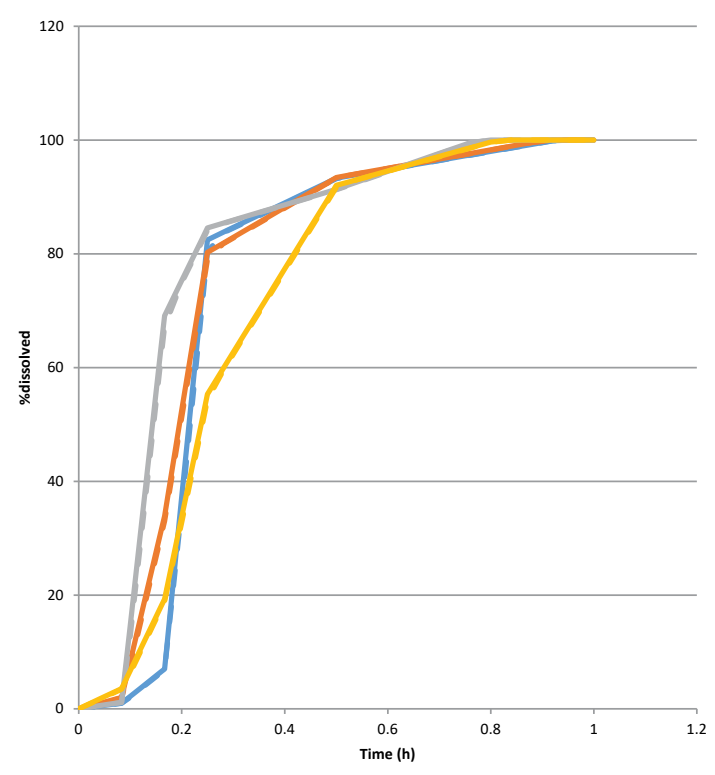

Figure 4. Dissolution profiles of capsules (solid lines) compared against those predicted when simulating using the "CRU Integral Tablet" dosage form (dashed lines). (Blue= ACG Nature Caps; Orange= ACG Nature Caps Plus; Grey= Quali-V; Gold= Vcaps Plus; CRU, controlled release undissolved).

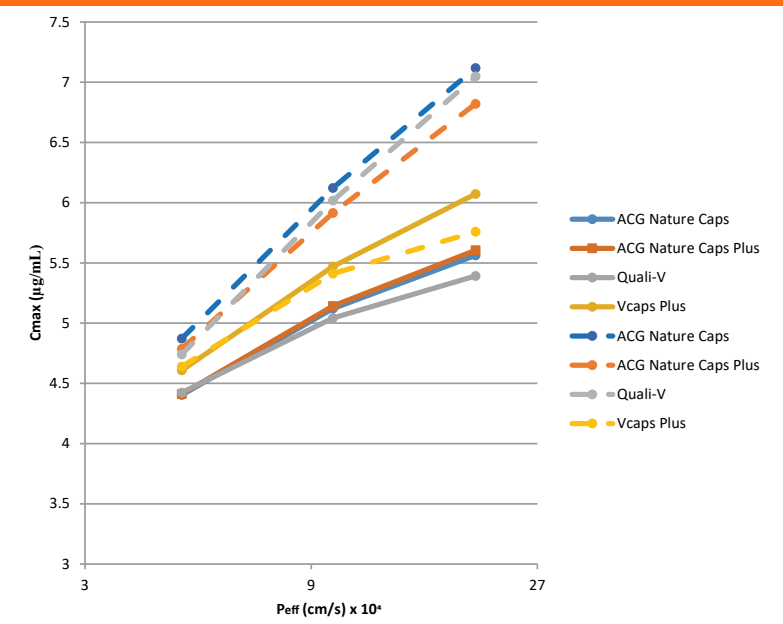

Figure 5. Effect of varying the given permeability ( $P_{\text {eff) }}$ on the $C_{\max }$ resulting from the simulation. Solid lines show simulations performed using the default gastric emptying time of $0.25 \mathrm{~h}$. Dashed lines show simulations performed assuming very rapid gastric emptying of $0.01 \mathrm{~h}$.

combinations of hypothetical $P_{\text {eff }}$ and gastric emptying time values, and the effect on $C_{\max }$ was observed. The results are shown in Figure 5 . Increasing the $P_{\text {eff }}$ value increased the $C_{\max }$ values more and made the differences between the different capsules larger than assuming very rapid gastric emptying, indicating that drug absorption in the simulations is determined first by the permeation rate through the intestinal epithelium and second by the gastric emptying rate, despite the drug being highly permeable (5). 
This indicates that either the $f_{2}$ factor $\geq 50$ criterion for dissolution profile similarity could be too strict for some rapidly dissolving formulations, unless the permeability is very high or strongly intestinal segment-dependent. This is in line with findings of Kovacevic et al (10). In addition, the permeation rate could still limit the overall absorption rate to a no lesser extent than gastric emptying rate, even for some highly permeable BCS class I compounds. With the current regulations, there could be cases where $f_{2}$ value comparison is performed on drug products with bioavailability that is affected by their drug release rate to an extent lesser than required for a difference corresponding to $f_{2}<50$, resulting in a significant difference in the in vivo performance. This could lead to assuming a product is dissimilar to its comparator based on the $f_{2}$ value being lower than 50 despite the in vivo performance being similar.

Of note is the slightly higher $\mathrm{C}_{\max }$ of Vcaps Plus compared to the rest of the capsules, despite its apparently slower dissolution rate. A large portion of API is released after the default gastric emptying time of $0.25 \mathrm{~h}$, which means that more of the API will be released without the gastric emptying rate being convoluted into its overall absorption profile. This explanation is supported by the fact that when very quick gastric emptying is assumed, the $C_{\max }$ of Vcaps Plus becomes slightly lower than that of the rest. This shows how extrapolating in vitro observations to the in vivo situation is often not straightforward.

\section{CONCLUSION}

Using HPMC capsules from different manufacturers could, at least from a regulatory point of view, result in significant differences in the dissolution performance for highly soluble drugs like acetaminophen, where drug dissolution could be so fast that the capsule shell rupture and dissolution rates would be reflected in the overall drug release profile. However, these differences might not always be reflected by significant differences in the in vivo performance. This is because drug dissolution is not always the rate-determining step of drug absorption. In such cases, a dissolution profile similarity criterion of $f_{2} \geq$ 50 could often be too strict, particularly in the absence of strong segment-dependence of the API's permeability. Therefore, it would be reasonable to look further into relaxing the current dissolution profile similarity criterion in such cases and/or investigate the use of some alternative dissolution comparison methods (with better ability to forecast the differences in the in vivo product performance) following further study of the interplay between dissolution, gastric emptying and absorption rates.

\section{ACKNOWLEDGEMENTS}

This work is contributed as sideground to the OrBiTo Initiative Joint Undertaking (http://www.imi.europa.eu).

\section{DISCLOSURES}

The authors disclosed no funding or potential conflicts of interest relevant to this article.

\section{REFERENCES}

1. CHMP Assessment Report for Pradaxa; EMEA/174363/2008; European Medicines Agency: London, 2008.

2. Gullapalli, R.P. Dissolution of Liquid-Filled Capsules Based Formulations. Ch. 18 in Poorly Soluble Drugs: Dissolution and Drug Release; Webster, G.K., Jackson, J.D., Bell, R.G., Eds. Pan Stanford Series on Pharmaceutical Analysis; Pan Stanford Publishing Pte. Ltd.: Singapore, 2017; Vol 1.

3. Tukker, J.J.; Sitsen, J.M.A.; Gusdori, Ch. F. Bioavailability of paracetamol after administration to healthy volunteers: influence of caffeine on rate and extent of absorption. Pharm. Weekbl. Sci. Ed. 1986, 8, 239-243. DOI: 10.1007/BF01957785.

4. Walter-Sack, I.; Luckow, V.; Guserle; Weber, E. Untersuchungen der relativen Bioverfügbarkeit von Paracetamol nach Gabe von festen und flüssigen oralen Zubereitungen sowie rektalen Applikationsformen. [The relative bioavailability of paracetamol following administration of solid and liquid oral preparations and rectal dosage forms.] [in French] Arzneimittelforschung. 1989, 39, 719-724.

5. Kalantzi, L.; Reppas, C.; Dressman, J.B.; Amidon, G.L.; Junginger, H.E.; Midha, K.K.; Shah, V.P.; Stavchansky, S.A.; Barends, D.M. Biowaiver monographs for immediate release solid oral dosage forms: acetaminophen (paracetamol). J. Pharm. Sci. 2006, 95, 4-14. DOI: 10.1002/jps.20477.

6. Lennernäs, H. Human in vivo regional intestinal permeability: importance for pharmaceutical drug development. Mol. Pharm. 2014, 114, 12-23. DOI: 10.1021/mp4003392.

7. Ku, M.S.; Lu, Q.; Li, W.; Chen, Y. Performance qualification of a new hypromellose capsule: Part II. Disintegration and dissolution comparison between two types of hypromellose capsules. Int. J. Pharm. 2011, 416,16-24. DOI: 10.1016/j.ijpharm.2011.02.048.

8. McConnell, E.L.; Fadda, H.M.; Basit, A.W. Gut instincts: explorations in intestinal physiology and drug delivery. Int. J. Pharm. 2008, 364 (2), 213-226. DOI: 10.1016/j. ijpharm.2008.05.012. 
9. Waiver of in vivo bioavailability and bioequivalence studies for immediate-release solid oral dosage forms based on a biopharmaceutics classification system. U.S. Department of Health and Human Services, Food and Drug Administration, Center for Drug Evaluation and Research (CDER): Silver Spring, MD; December 2017.

10. Kovačevi, I.; Parojči, J.; Tubi-Grozdanis, M.; Langguth, P. An investigation into the importance of "very rapid dissolution" criteria for drug bioequivalence demonstration using gastrointestinal simulation technology. AAPS J. 2009, 11, 381384. DOI: 10.1208/s12248-009-9114-3. 